\title{
CAPÍTULO 05: RECURSOS PARA O PROCESSO DE ENSINO DE MATEMÁTICA: UM ESTUDO COM PROFESSORES QUE LECIONAM MATEMÁTICA NA EDUCAÇÃ̃O BÁSICA
}

\author{
CAPÍTULO 05: RECURSOS PARA EL PROCESO DE ENSEÑANZA DE \\ MATEMÁTICAS: UN ESTUDIO CON PROFESORES QUE ENSEÑAN \\ MATEMÁTICAS EN EDUCACIÓN BÁSICA
}

\section{CHAPTER 05: RESOURCES FOR THE MATHEMATICS TEACHING PROCESS: A STUDY WITH TEACHERS WHO TEACH MATHEMATICS IN BASIC EDUCATION}

\author{
Franklin Fernando Ferreira Pachêco ${ }^{1}$; Alan Gustavo Ferreira²; Valéria da Silva Santos ${ }^{3}$
}

DOI: https://doi.org/10.31692/978-65-88970-05-8.63-80

\begin{abstract}
RESUMO
A presente pesquisa analisou como professores que lecionam matemática compreendem a ideia de recursos para planejar aulas, desenvolver e explorar conteúdos matemáticos no ambiente da sala de aula. Para dá suporte a esse método investigativo, adotou-se a discussão de Adler que categoriza recursos em três tipos (Material, Humano e Cultural). Participaram dessa pesquisa 15 professores que ensinam a disciplina de Matemática na Educação Básica. O instrumento proposto para coletar os resultados se tratou de um formulário eletrônico com quatro questões todas sobre recursos. A primeira questão teve por objetivo verificar quais os tipos de recursos são conhecidos pelos professores. A segunda questão propôs identificar quais os subtipos de recursos os professores consideram úteis para o processo de ensino de conteúdos da Matemática. A terceira questão teve o intuito de identificar a compreensão dos professores sobre como ocorre o processo de integração de recursos no ambiente da sala de aula. A quarta questão concebeu como propósito compreender a importância que os professores atribuem aos recursos. Foram realizadas para todas essas questões análises a priori destacando possíveis acertos e erros que poderiam ser mobilizadas por professores que lecionam matemática ao respondê-las. Os resultados foram categorizados e analisados sob a ótica de recursos proposta por Adler. Verificou-se como resultados que os participantes mostraram um desempenho pertinente sobre a noção de recurso e como usá-los no ambiente da sala de aula, mas também se observou a necessidade de aprofundar os tipos e subtipos de recursos com esses profissionais. Esses resultados potencializam o quanto é interessante que o professor que leciona a disciplina de Matemática conceba a percepção de que independentemente do tipo ou subtipo de recurso usado no ambiente escolar são as ações pedagógicas que permitem ao material atribuir sentido ao conteúdo explorado, por isso é essencial existir planejamento para integrar recurso na sala de aula.

Palavras-Chave: Professores, Processo de ensino e de aprendizagem, Recursos.
\end{abstract}

\section{RESUMEN}

Esta investigación analizó cómo los profesores que enseñan Matemáticas entienden la idea de recursos para planificar clases, desarrollar y explorar contenido matemático en el ambiente del aula. Para apoyar este método de investigación, se adoptó la discusión de Adler, que clasifica los recursos en tres tipos (materiales, humanos y culturales). En esta investigación participaron quince profesores que imparten la asignatura de Matemática en Educación Básica. El instrumento propuesto para la recolección de resultados fue un formulario electrónico con cuatro preguntas todas sobre recursos. La primera pregunta

1 Doutorando em Educação Matemática e Tecnológica, Universidade Federal pacheco.franklin9@gmail.com

2 Doutorando em Educação Matemática Alan.Gustavo@hotmail.com

3 Mestre em Educação valeriassantos22@hotmail.com
Matemática e Tecnológica, Universidade-Federal

Tecnológica, Universidade

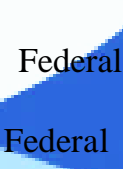

Pernambuco,

Pernambuco,

Pernambuco, 
tenía como objetivo verificar qué tipos de recursos conocen los profesores. La segunda pregunta propuso identificar qué subtipos de recursos los profesores consideran útiles para el proceso de enseñanza de contenidos matemáticos. La tercera pregunta tenía como objetivo identificar la comprensión de los profesores sobre cómo se produce el proceso de integración de recursos en el entorno del aula. La cuarta pregunta se diseñó para comprender la importancia que los profesores conceden a los recursos. Se realizaron análisis priori para todas estas preguntas, destacando posibles respuestas correctas y errores que podrían ser movilizados por los profesores que enseñan Matemáticas al responderlas. Los resultados fueron categorizados y analizados desde la perspectiva de recursos propuesta por Adler. Se encontró como resultado que los participantes mostraron un desempeño relevante sobre la noción de recurso y cómo utilizarlos en el ambiente del aula, pero también hubo necesidad de profundizar los tipos y subtipos de recursos con estos profesionales. Estos resultados realzan lo interesante que es que el docente que imparte la asignatura de Matemáticas conciba la percepción de que independientemente del tipo o subtipo de recurso utilizado en el ámbito escolar, son las acciones pedagógicas las que permiten que el material asigne significado al contenido explorado, por lo que es imprescindible que exista. planeando integrar recursos en el aula.

Palabras Clave: Docentes, Proceso de enseñanza y aprendizaje, Recursos

\begin{abstract}
This research analyzed how teachers who teach Mathematics understand the idea of resources to plan classes, develop and explore mathematical content in the classroom environment. To support this investigative method, Adler's discussion was adopted, which categorizes resources into three types (Material, Human and Cultural). Fifteen teachers participated in this research who teach the subject of Mathematics in Basic Education. The instrument proposed to collect the results was an electronic form with four questions all about resources. The first question aimed to verify which types of resources are known to teachers. The second question proposed to identify which subtypes of resources teachers consider useful for the process of teaching mathematical content. The third question was intended to identify the teachers' understanding of how the process of integrating resources occurs in the classroom environment. The fourth question was designed to understand the importance that teachers attach to resources. Priori analysis were performed for all these questions, highlighting possible correct answers and errors that could be mobilized by the teachers who teach Mathematics when answering them. The results were categorized and analyzed from the resource perspective proposed by Adler. It was found as a result that the participants showed a relevant performance on the notion of resource and how to use them in the classroom environment, but there was also a need to deepen the types and subtypes of resources with these professionals. These results enhance how interesting it is that the teacher who teaches the subject of Mathematics conceives the perception that regardless of the type or subtype of resource used in the school environment, it is the pedagogical actions that allow the material to assign meaning to the explored content, so it is essential to exist planning to integrate resource in the classroom.

Keywords: Teachers, Teaching and learning process, Resources.
\end{abstract}

\title{
INTRODUÇÃO
}

A Matemática, ciência originada por intermédio da necessidade humana, está presente na vida social e escolar do homem. Na vida social, ela está em diversas situações (política, comércio, etc.). No âmbito escolar essa ciência está presente em toda Educação Básicá e seus conteúdos encontram-se organizados por ano escolar, por meio de unidades temáticas, com progressivo aumento de complexidade em cada etapa de escolaridade, como apresenta a Base

Nacional Comum Curricular/ BNCC (BRASIL, 2018).

Sendo essa ciência composta por conteúdos de caráter abstratos não é possível acessar 
seus conhecimentos, por isso ao estudar Matemática é necessário recorrer a representações de seus objetos. Entende-se que a abstração é um dos fatores principais que tem inquietado os alunos para compreender à disciplina de Matemática, por isso os professores que a ensinam buscam alternativas para despertar o interesse de seus alunos. Nesse contexto, na maioria das vezes, os professores se apoiam no uso de recursos para explorar os conteúdos de Matemática.

Usar recursos para ensinar conteúdos da Matemática é uma recomendação proposta pelos Parâmetros Curriculares Nacionais/PCN (BRASIL, 1997; 1998) e BNCC (BRASIL, 2018), documentos de orientações curriculares nacionais, que norteiam o processo de ensino e de aprendizagem da Matemática. Entretanto, é necessário que essa integração ocorra com finalidades pedagógicas bem definidas pelos professores para que o trabalho com recursos contribuam para propiciar aprendizagens nos alunos sobre o conteúdo vivenciado na sala de aula. Ou seja, ao considerar que recurso é tudo aquilo que contribui para o professor, a partir de sua metodologia de ensino, promover à aprendizagem de seus alunos é interessante que esses profissionais reflitam possíveis maneiras de conduzir o trabalho com recursos associados aos conteúdos da Matemática.

Para Adler (2000) "a noção de sentido comum dos recursos na e para a educação é o recurso como objeto material, e a falta de recursos geralmente se refere à escassez de livros didáticos e outros materiais de aprendizagem.” (p. 207). De fato, no Brasil, pesquisas (CARVALHO; LIMA, 2010; BARBOSA; LINS, 2013; BITTAR, 2017; PACHÊCO; SILVA, 2019) já realizadas destacam que o Livro Didático é o recurso mais usual pelo professor para promover o processo de ensino e de aprendizagem de seus alunos.

Ao verificar que a ênfase do recurso no contexto educacional é do tipo Material, Adler (2000) amplia a categorização de recursos para os de tipo Material, Humano e Cultural. Esse estudo foi realizado na perspectiva de formação de professores de Matemática, na África do Sul, no período pós-apartheid. Os resultados apresentados apontam para uma reflexão de como os professores que ensinam Matemática devem usar recursos no ambiente escolar. Destaca ainda, que a formação de professores de Matemática deve se concentrar com mais ênfase para entender o que são os recursos, como usá-los e como eles podem se tornar uma extensão dos professores no contexto escolar.

Com base nessas reflexões, a presente pesquisa tem por objetivo geral: analisar como professores que lecionam Matemática compreendem a ideia de recursos para planejar aulas, desenvolver e explorar conteúdos matemáticos no ambiente da sala de aula. Para dá suporte a esse método investigativo, adotou-se a discussão de Adler (2000) sobre recursos.

Tem-se como participantes professores que ensinam a disciplina-de Matemática em 
escolas públicas (municipal e estadual) e privadas. Discutidos os elementos da pesquisa, a seguir é exposto a revisão da literatura, seguida pelos procedimentos metodológicos, análises e discussões dos resultados, considerações finais e as referências.

\section{RECURSOS PARA O ENSINO DE CONTEÚdOS DE MATEMÁTICA}

Nesse texto, a conceituação de recursos está apoiada por meio de estudos realizados sob a perspectiva da formação de professores e a prática da Matemática escolar. Essa investigação foi vivenciada com professores de Matemática, na África do Sul, pós-apartheid, em escolas de campo. (ADLER, 2000).

De modo semelhante às escolas da África do Sul, no Brasil “o ensino de Matemática em escolas do Campo precisam ampliar a perspectiva e valorizar a dimensão humana e a cultural dos recursos.” (MONTEIRO, 2016, p. 4).

Um dos argumentos destacado por Adler é que independente se a escola possui ou não uma variedade de recursos sempre alguns professores, em atuação de seu exercício, estarão se lamentando sobre a falta de recursos. Sobre isso, essa autora elenca que o recurso por si não melhora a prática escolar. De fato, nenhum recurso atua sozinho, portanto, sendo relevante que exista um professor que atribua ação sobre os recursos com "finalidades pedagógicas com o intuito de evidenciar um melhor processo de ensino." (PACHÊCO; ANDRADE; SILVA, 2019, p. 126).

Para Adler (2000), uma possível conceituação para resource (recurso) é compreendê-lo enquanto um nome e como um verbo. Ao se apoiar em um recurso, o profissional deve agir sobre ele para torná-lo um suporte para o processo de ensino de modo a contribuir para a aprendizagem de seus alunos. Por isso, essa autora propõe que a formação inicial e continuada de professores foque com mais ênfase na discussão sobre recursos e suas atribuições para o ensino de conteúdos da Matemática, mas que não se limitem aos objetos materiais e reconheçam as especificidades cotidianas (temporais e culturais) e espaciais de cada escola.

Nessa perspectiva, Adler (2000) categoriza recursos em três tipos (Material, Humano e Cultural). Essas informações constam no quadro 01.

Quadro 01: Categorização de recursos proposta por Adler (2000)

\begin{tabular}{|c|c|c|c|c|}
\hline \multicolumn{1}{|c|}{ Quadro 01: Categorização de recursos proposta por Adler (2000) } \\
\hline $\begin{array}{c}\text { Tipos de } \\
\text { recursos }\end{array}$ & \multicolumn{4}{|c|}{ Subtipos de recursos } \\
\hline & Tecnologias & $\begin{array}{c}\text { Materiais } \\
\text { escolares }\end{array}$ & $\begin{array}{c}\text { Objetos } \\
\text { matemáticos }\end{array}$ & $\begin{array}{c}\text { Objetos do } \\
\text { cotidiano }\end{array}$ \\
\hline
\end{tabular}




\begin{tabular}{|c|c|c|c|c|}
\hline Material & $\begin{array}{c}\text { Exemplo: } \\
\text { Quadro }\end{array}$ & $\begin{array}{c}\text { Exemplo: } \\
\text { Cartazes }\end{array}$ & $\begin{array}{c}\text { Exemplo: } \\
\text { Plano cartesiano }\end{array}$ & $\begin{array}{c}\text { Exemplo: } \\
\text { Estórias }\end{array}$ \\
\hline \multirow{2}{*}{ Humano } & \multicolumn{2}{|c|}{ Pessoa } & Processos \\
\cline { 2 - 4 } & Exemplo: Professor & Exemplo: Qualificação profissional \\
\hline \multirow{3}{*}{ Social cultural } & Linguagem & Tempo \\
\cline { 2 - 4 } & Exemplo: Lingua falada & Exemplo: Calendário escolar \\
\hline
\end{tabular}

Fonte: Elaborado pelos autores baseado em Adler (2000)

Adler ao ampliar o conceito de recurso além dos materiais quis destacar que o "reconhecimento do humano e da cultura enquanto recursos possibilita a valorização de aspectos que, de certa maneira, são colocados como invisíveis no processo de ensinar e aprender Matemática." (MONTEIRO, 2016, p. 3).

Ao observar a categorização de recursos, exposta no quadro 01, é possível destacar que o contexto educacional tem um maior foco nos de tipos Material e Humano. Ao considerar as informações contidas no quadro 01 para a Matemática escolar é possível destacar os seguintes elementos dos recursos do tipo:

- Material:

$\checkmark$ Tecnologias - nesse contexto, as tecnologias podem ser compreendidas desde o simples quadro comum até um computador;

$\checkmark$ Materiais de Matemática - são objetos produzidos especificamente para a Matemática escolar;

$\checkmark$ Objetos matemáticos - emergem no contexto escolar (disciplina e/ou academia), podendo ser uma representação de algum objeto matemático (quadrilátero) até teoremas ou etc.;

$\checkmark$ Objetos cotidianos - estão explicitamente no contexto social do ser humano contribuindo para a abordagem de conhecimentos da Matemática (calculadora, régua, dinheiro, etc.);

\section{- Humano:}

$\checkmark$ Pessoal - professor que leciona Matemática;

$\checkmark$ Processos - Qualificação profissional adquirida ao longo dos anos para promover o conhecimento no ambiente da sala de aula são recursos;

\section{- Cultural:}


$\checkmark$ Linguagem - é um recurso por ser compreendida como tridimensional (cultural, social e contexto);

$\checkmark$ Tempo - esse recurso pode ser compreendido ao ser usado em distintos contextos, por exemplo, na zona urbana e rural. "No entanto, em todos os contextos, o tempo funciona de forma formativa na escola por meio de horários, duração dos períodos e possibilidades de dever de casa. Ele estrutura a prática da Matemática escolar para produzir tarefas de estimulação, sequenciação e tempo.” (ADLER, 2000, p. 211).

A presente pesquisa se apoia nessas categorizações de recursos para analisar e discutir os resultados. O próximo tópico aborda os procedimentos adotados para o desenvolvimento da investigação.

\section{METODOLOGIA}

Esta pesquisa de ênfase exploratória, com abordagem qualitativa, se propôs a analisar como professores que lecionam Matemática compreendem à ideia de recursos para planejar aulas, desenvolver e explorar conteúdos matemáticos no ambiente da sala de aula. Para atender a essa proposta investigativa, convidou-se por meio do aplicativo WhatsApp professores que lecionam a disciplina de Matemática na Educação Básica que quisessem contribuir voluntariamente para o estudo. Após eles aceitarem o convite foi encaminhado o formulário eletrônico ${ }^{1}$, constituído por quatro questões, para a apreciação e resolução.

Optou-se por professores que ensinam Matemática na Educação Básica por serem esses os profissionais que promovem o processo de ensino para seus alunos. Ao considerar que às aulas de Matemática não devem ser relegadas pelos alunos, mas fazer sentido para esses construírem seus conhecimentos e se tornarem ao longo da Educação Básica preparados para enfrentar uma vida acadêmica, profissional e social, uma das alternativas mais usadas pelos professores para despertar o interesse dos alunos é integrar recursos no ambiente da sala de aula para trabalhar o conteúdo que está sendo abordado ao longo das aulas.

As questões integradas no formulário eletrônico foram apoiadas na ideia de recursos proposta por Adler (2000). Sob essa perspectiva, a presente pesquisa teve a intenção de entender o que são recursos para professores que lecionam Matemática. Cada uma teve um propósito a ser alcançado e refletido nesse texto.

Intitulou-se o formulário de "Estudo sobre recursos e professores que lecionam

\footnotetext{
${ }^{1} \mathrm{O}$ prazo para responder às questões da pesquisa ocorreu entre os dias 31/08/2020 até 05/09/2020.
} 
Matemática" e disponibilizou-se algumas informações para situar os professores pesquisados sobre o que se tratava o estudo. Informações essas expostas na figura 01.

Figura 01: Informações iniciais do formulário eletrônico

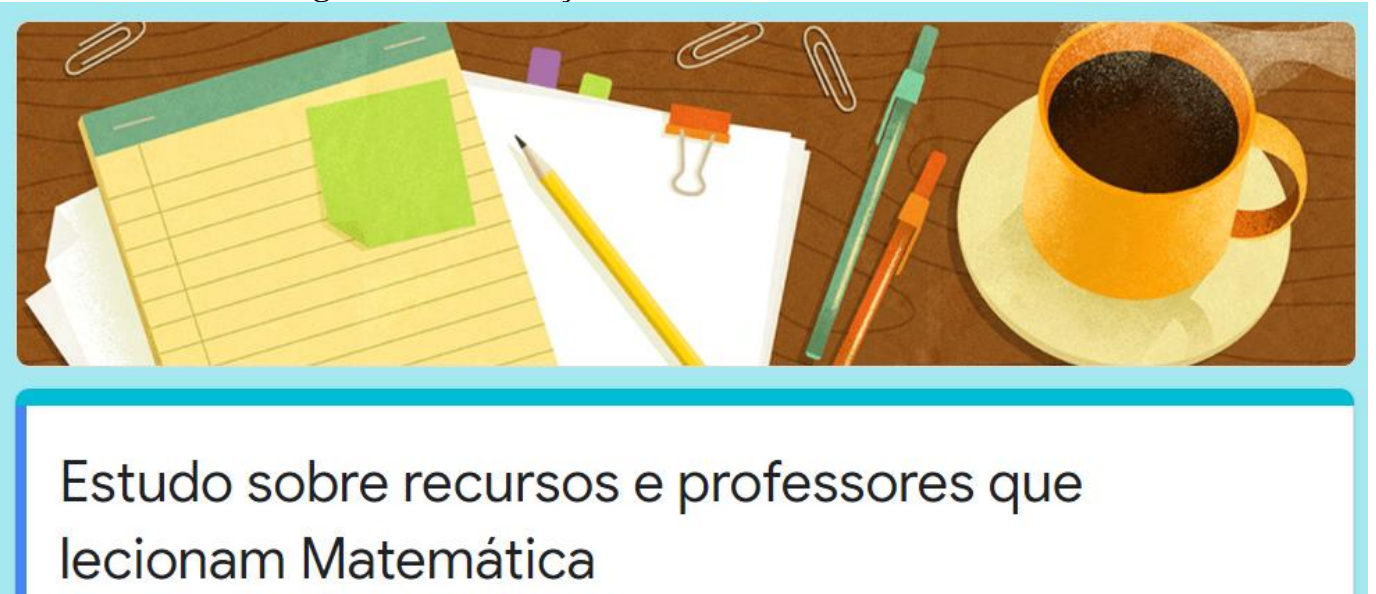

Os questionamentos presentes nesse formulário eletrônico integram uma pesquisa científica em desenvolvimento que se situa no âmbito da Educação Matemática que investiga a compreensão de recursos por professores que lecionam Matemática na Educação Básica.

\section{Fonte: Elaborado pelos autores}

Em seguida, como expõe a figura 02, solicitou-se que os professores escolhessem um pseudônimo. Feito isso assinalassem em qual etapa escolar da Educação Básica (educação infantil ou ensino fundamental - anos iniciais ou finais ou ensino médio) e a rede de ensino (privada ou pública) exercem suas funções profissionais.

Figura 02: Conhecendo o perfil profissional dos professores pesquisado

Olá, professor. Solicita-se, nesse momento, que você escolha um pseudônimo, a seu critério, para responder as questões do formulário eletrônico. *

Your answer

Professor, em qual etapa escolar da Educação Básica você leciona a disciplina de Matemática? Qual a rede de ensino que você atua (pública ou privada)? *

Educação Infantil (Escola pública)

Ensino Fundamental anos iniciais (Escola pública)

Ensino Fundamental anos finais (Escola pública)

Ensino Médio (Escola pública)

Educação Infantil (Escola privada)

Ensino Fundamental anos iniciais (Escola privada)

Ensino Fundamental anos finais (Escola privada)

Ensino Médio (Escola privada)

Fonte: Elaborado pelos autores 
Participaram desse estudo 15 professores com os psedônimos de: Gustavo, João, Catarina, Jonata, Girassol, Rivaldo, 2A, Ramos, Asclépio, Estela, Nosde, Anderson, IJ, Josinaldo e Zé. Dentre eles, em relação a rede de ensino, obtevê-se o total de que:

- 6 professores lecionam apenas no ensino médio em escolas públicas;

- 3 professores ensinam apenas nos anos finais do ensino fundamental em rede pública;

- 2 professores ensinam nos anos finais do ensino fundamental e ensino médio, ambas instituições sendo públicas;

- 1 professor leciona nos anos finais do ensino fundamental e ensino médio, ambas instituições de caratér privada;

- 1 professor que exerce sua função no ensino fundamental anos finais na rede privada;

- 1 professor que trabalha nos anos finais do ensino fundamental em instituição pública e privada;

- 1 professor que exerce sua função no ensino médio em escola privada.

Essas informações estão expostas na figura 03 que são geradas pela plataforma usada (google forms) ao responder os questionamentos.

Figura 03: Respostas dos professores em relação a instituição de ensino (pública e/ou privada)

15 responses

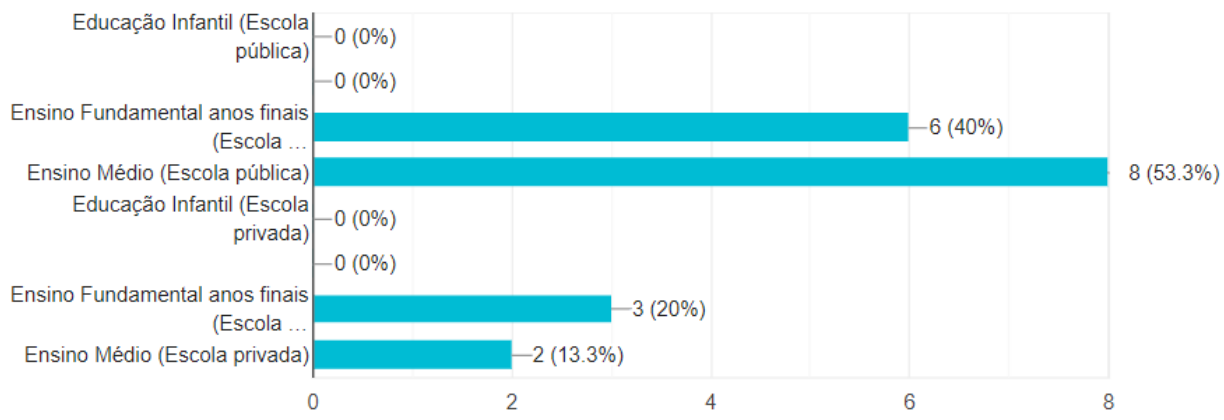

Fonte: Dados da pesquisa

Conforme as informações expostas no gráfico da figura 03, observou-se que não houve participantes que lecionam na educação infantil.

Em relação às questões presentes no formulário eletrônico, elaborou-se para cadá uma delas uma análise a priori. Essa discussão dos possíveis resultados que os professores que lecionam Matemática poderiam expressar ao resolver as questões individual teve $o$ propósito de destacar a pluralidade de resultados que podem emergir quando distintos participantes se confrontam com uma mesma atividade. A primeira questão exposta por meio da figura 04 abordou os tipos de recursos (Material, Humano e Cultural) categorizados por Adler (2000). O 
seu intuito foi o de verificar quais os tipos de recursos são conhecidos pelos professores.

Figura 04: Primeira questão

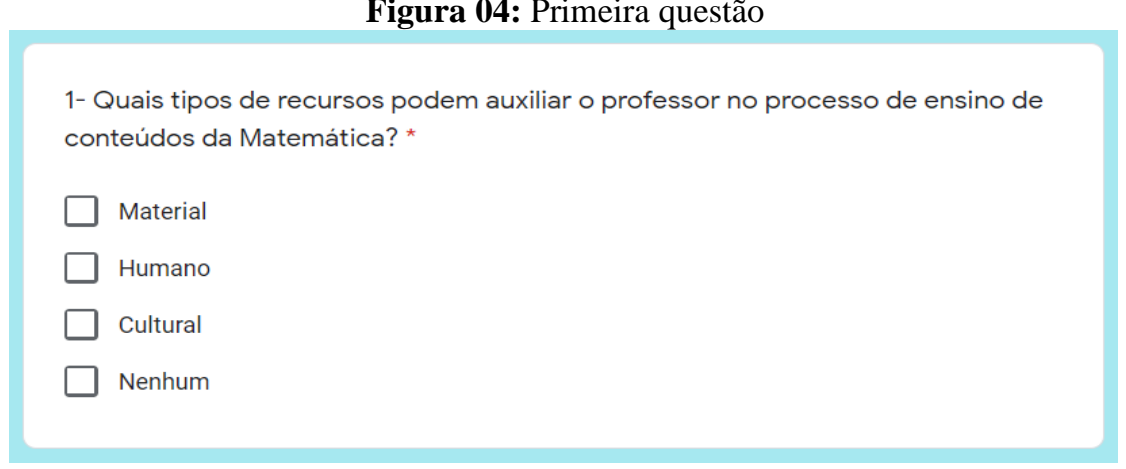

Fonte: Elaborado pelos autores

Infere-se que dentre os tipos de recursos (Material, Humano e Cultural) explorado o mais usual e conhecido pelos professores no ambiente da sala de aula para trabalhar com os conteúdos de Matemática são os de caráter Material. Por isso, o previsto é que a alternativa mais escolhida como correta seja a que corresponde ao recurso Material, seguida pela opção de recursos Humano e por último recurso Cultural.

A segunda questão, conforme mostra a figura 05, abarcou exemplos de subtipos (Tecnologias, Materiais matemáticos escolares, objetos Matemáticos e objetos do dia-adia/Material; Pessoa e processo/Humano; Linguagem e Tempo/Cultural) de recursos destacados por Adler (2000). O objetivo dessa questão foi identificar quais subtipos de recursos os professores consideram úteis para o processo de ensino de conteúdos da Matemática.

Figura 05: Segunda questão

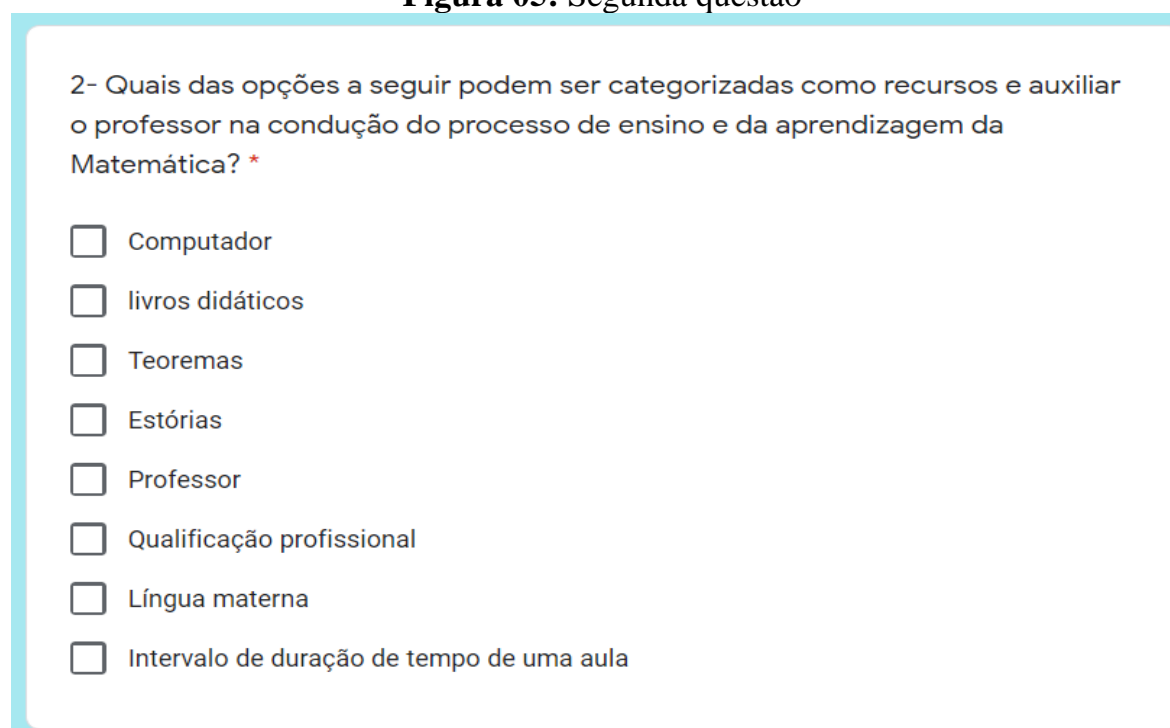

Fonte: Elaborado pelos autores

Nesta questão, esperou-se que os professores não marcassem as opções (Professor e Qualificação profissional que são categorizadas como recursos dos subtipos pessoa e processo, 
respectivamente.). Acredita-se, a princípio, que esses subtipos de recursos não serão assinalados porque os professores, apesar de usarem implicitamente esses recursos, em sua grande maioria, não sabem que são um suporte para o ensino.

Os demais subtipos de recursos são mais usuais no ambiente da sala de aula, por isso se esperou que elas sejam marcadas como opções corretas. Dentre as opções, infere-se que as opções computador, livros didáticos, teoremas e estórias serão as mais assinaladas, seguida pelas alternativas língua materna e intervalo de duração de tempo de uma aula.

Ao considerar a finalidade dos recursos para o processo de ensino e de aprendizagem, a terceira questão propôs a identificar a compreensão dos professores sobre como ocorre o processo de integração de recursos no ambiente da sala de aula. Essas informações estão presentes na figura 06.

Figura 06: Terceira questão

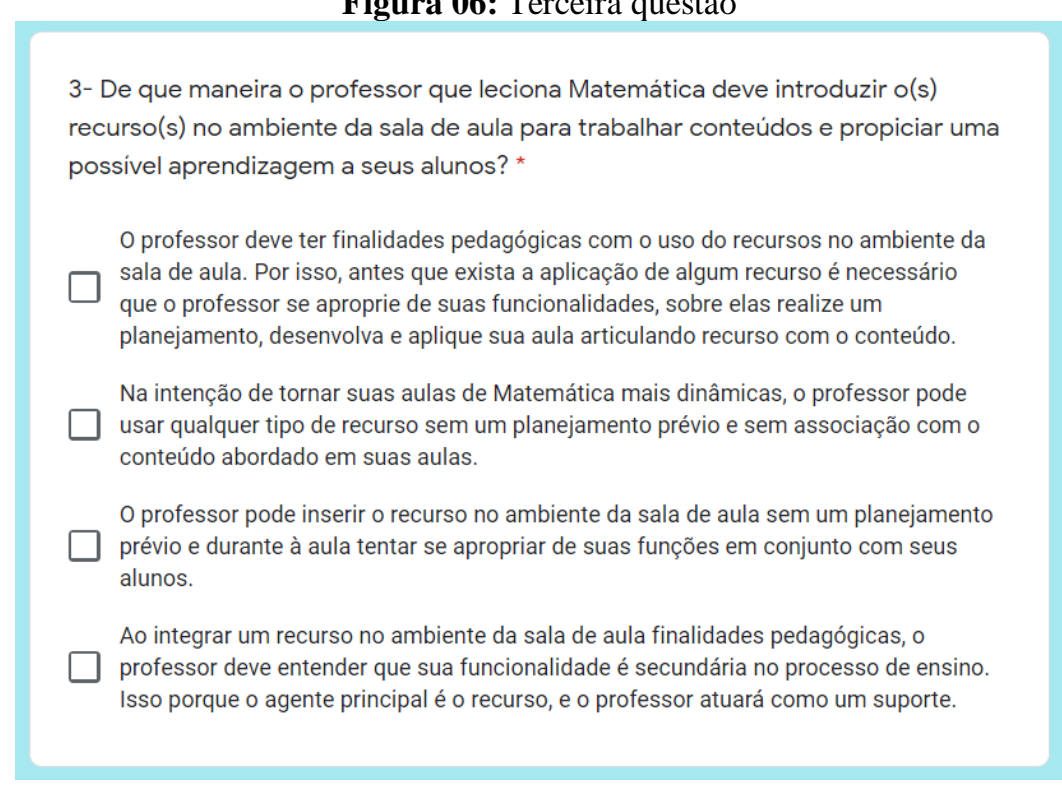

Fonte: Elaborado pelos autores

Nesta questão, espera-se que os professores assinalassem como correta a primeira alternativa. Isso porque ela possibilita a compreensão de que o uso de recursos no ambiente da sala de aula pelo professor deve ter finalidade pedagógica com objetivos bem definidos para promover um melhor entendimento do conteúdo trabalhado para seus alunos. Além disso, é interessante que o profissional da educação esteja, antes da aplicação do recurso na sala de aula, apropriado com as ferramentas dos recursos para saber como usá-las mediante a exploração do conteúdo. As demais opções podem ser relegadas como verdadeira pelo fato de desconsiderar o planejamento e a relevância profissional como um produto essencial para integração de recursos no ambiente da sala de aula.

A quarta questão, conforme expõe a figura 07, teve como propósito compreender a 
importância que os professores atribuem aos recursos. Isso porque o recurso, independente se for ou não tecnológico, não atua sozinho sendo necessário uma intervenção profissional para contribuir no processo de ensino.

Figura 07: Quarta questão

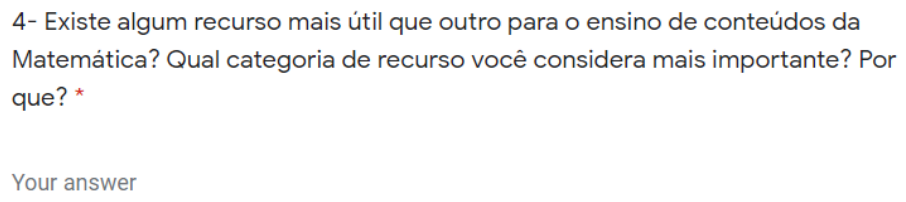

Fonte: Elaborado pelos autores

O esperado como respostas para essas indagações que integram a quarta questão é que os professores frisem que não existe um recurso mais útil que o outro, mas a forma como esse é integrado pelo professor na sala de aula pode ter finalidades distintas para alcançar o mesmo ou diferentes objetivos sobre um conteúdo. Assim sendo, quem definirá os encaminhamentos sobre como e o modo de usar o recurso é a metodologia do professor.

Em oposição, caso os professores respondam que existem recursos mais úteis que outros infere-se que os tecnológicos serão os mais citados como os mais relevantes e completos para o processo de ensino e de aprendizagem sobre os conteúdos de Matemática.

A discussão dos resultados está organizada por meio de dois momentos. No primeiro, verifica-se a quantidade possível de participantes que acertaram totalmente o questionário, acertaram parcialmente o questionário e erraram totalmente o questionário.

No segundo momento as análises dos resultados será por questão, ou seja, a princípio será realizado uma comparação entre a análise a priori e os resultados dos professores. Em seguida, expõe-se detalhadamente o porquê dos acertos cometidos pelos participantes. A seguir, o próximo tópico aborda os resultados dessa pesquisa.

\section{RESULTADOS E DISCUSSÃO}

De modo a contemplar o método investigativo, que se apoiou em verificar a compreensão de professores sobre recursos, os resultados foram analisados sob a ótica de Adler (2000) e categorizados em dois momentos.

Conforme descrito nos procedimentos metodológicos, o primeiro momento verificou a quantidade de participantes que acertaram totalmente ou parcialmente o questionário ou erraram todas as questões. Considerou-se acertaram todas as questões (os professores que responderam corretamente todas as questões), acertaram parcialmente as questões (os 
professores que responderam corretamente uma, duas ou três das quatro questões ou ainda que acertaram três questões completas e uma parcialmente, pois existem questões (primeira e segunda), que são múltiplas escolhas, que possuem mais de uma alternativa correta) e erraram todas as questões (professores que responderam todas as questões erradas). Os resultados dessa categorização estão expressos na tabela 01.

Tabela 01: Resultado geral do questionário

\begin{tabular}{c|c|c|c}
\hline Categorias & $\begin{array}{c}\text { Acertaram todas as } \\
\text { questões }\end{array}$ & $\begin{array}{c}\text { Acertaram parcialmente } \\
\text { as questões }\end{array}$ & $\begin{array}{c}\text { Erraram todas as } \\
\text { questões }\end{array}$ \\
\hline $\begin{array}{c}\text { Quantitativo de } \\
\text { professores }\end{array}$ & 1 & 14 & Nenhum \\
\hline Percentual & $6,67 \%$ & $93,33 \%$ & $0 \%$ \\
\hline
\end{tabular}

Fonte: Dados da pesquisa

Por meio dos resultados da tabela 01, ao expressar um maior quantitativo de acertos parciais pelos professores, verifica-se que o entendimento desses participantes sobre o que é um recurso deve ser ampliado, por meio de leituras ou formações continuadas, levando-os a reflexões, para que exista por parte desses profissionais uma melhor e correta compreensão de forma a possibilitar a integração de algum tipo de recurso no ambiente da sala de aula com fins pedagógicos, de maneira adequada, associadas aos conteúdos, para assim promover o ensino de conteúdos matemáticos. Esses resultados corroboram com o pensamento de Adler (2000) quando destaca que a ideia do senso comum sobre recursos ou sua falta está mais associada ao uso do livro didático (Material).

Após a análise dos resultados dos professores de maneira geral, que ocorreu nessa seção por meio do primeiro momento, verificou-se as respostas por questão de forma a contemplar de modo mais detalhado os resultados.

A primeira questão teve por objetivo verificar quais os tipos de recursos são conhecidos pelos professores. Nela era permitido assinalar mais de uma opção, assim possibilitando marcar corretamente os tipos de recursos (Material, Humano e Cultural).

Os resultados, expressos na figura 08 , convergem com o discutido na análise a priori, ou seja, que dentre as opções de recursos o mais reconhecido seria o do tipo Material. Esse tipo de recurso obteve $100 \%$ de marcação, ou seja, todos os professores a consideraram como recurso.

Em contraposição, não era esperado que o tipo de recurso Cultural fosse mais reconhecido que o Humano pelos participantes. Isso porque, a História da Matemática apresenta que em tempos antigos partes do corpo (pé, mão, braço, etc.) já serviram de unidades de 
medidas para trabalhar com conhecimentos matemáticos.

Figura 08: Respostas dos professores ltado da questão 1

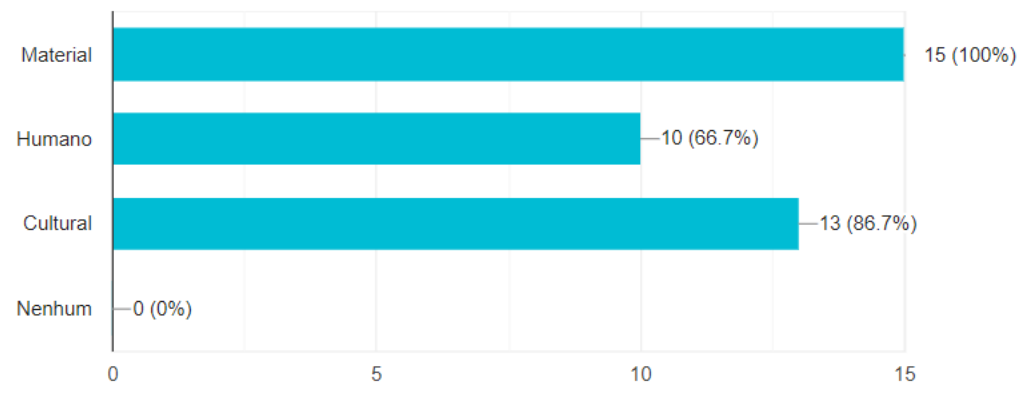

Fonte: Dados da pesquisa

Na análise a priori, partiu-se do pressuposto que o tipo de recurso Cultural seria o menos assinalado porque existem diversas, mas que no âmbito escolar os mais explorados no processo de ensino da Matemática são as contribuições do povo babilônico, egipcios, mesopotâmicos, chineses, gregos, maias, etc. Informações essas sempre disponibilizadas nos livros didáticos.

O intuito da segunda questão foi identificar quais subtipos de recursos os professores consideram úteis para o processo de ensino de conteúdos da Matemática. $\mathrm{Na}$ análise a priori discutiu-se que o computador, livros didáticos, teoremas e estórias seriam as mais assinaladas, o que de fato ocorreu. Apesar disso, não era esperado que as alternativas correspondentes a qualificação profissional, língua materna, professor e intervalo de duração de tempo de uma aula seriam tão consideradas como subtipos de recursos. Infere-se que esses resultados correspondem que os profissionais entendem que é possível explorar esses materiais na sala de aula, mas se apoiam com mais ênfase no tipo de recurso Material.

Assim como na primeira questão, os professores poderiam assinalar mais de uma alternativa, sendo nesse caso, todas as opções corretas. Os livros didáticos e o computador foram reconhecidos como materiais para o processo de ensino por todos os 15 professores (100\%), como é possível ver nos resultados estão expressos na figura 09.

Figura 09: Respostas dos professores sobre a questão 2

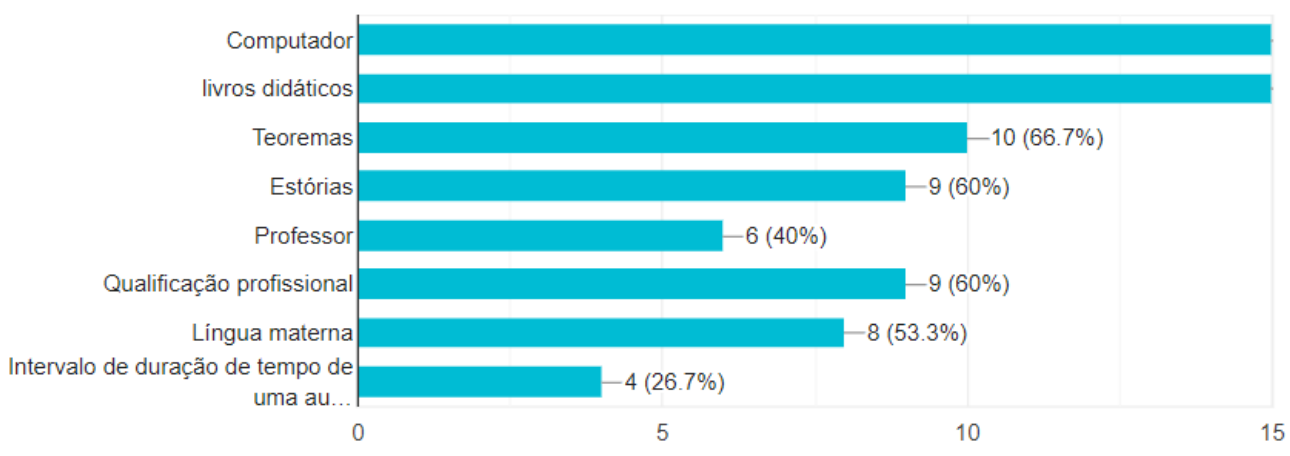

Fonte: Dados da pesquisa 
Outro aspecto relevante para ser destacado é que o intervalo de duração de tempo de uma aula foi o menos optado pelos professores, algo não previsto na análise a priori. O tempo é um conceito trabalhado na própria Matemática, por isso esperava-se que essa alternativa seria aceita como recurso pelos professores. É interessante destacar que o tempo pode ser atrelado a conteúdos da física, história, entre outros, sendo explorado com especificidade distintas em cada uma delas.

A terceira questão teve por objetivo identificar a compreensão dos professores sobre como ocorre o processo de integração de recursos no ambiente da sala de aula. O esperado nessa questão é que os professores considerassem a primeira alternativa como correta ( $O$ professor deve ter finalidades pedagógicas com o uso do recursos no ambiente da sala de aula. Por isso, antes que exista a aplicação de algum recurso é necessário que o professor se aproprie de suas funcionalidades, sobre elas realize um planejamento, desenvolva e aplique sua aula articulando recurso com o conteúdo.) por ser a única no qual apresenta que se deve ter finalidades pedagógicas pelos professores para integrar um recurso em sala de aula.

As demais opções não permitiam aos professores conduzirem um processo de integração de qualquer recurso de forma adequada no ambiente da sala de aula. Os resultados mostram que a segunda e quarta opções foram assinaladas por um professor. Entende-se que o devido docente marcou a opção dois (Na intenção de tornar suas aulas de Matemática mais dinâmicas, o professor pode usar qualquer tipo de recurso sem um planejamento prévio e sem associação com o conteúdo abordado em suas aulas.) por ela destacar o dinamismo de recursos, quando trabalhado na sala de aula, por isso desconsiderou o fato do planejamento prévio para o trabalho e associação com o conteúdo.

Infere-se que a quarta alternativa (Ao integrar um recurso no ambiente da sala de aula finalidades pedagógicas, o professor deve entender que sua funcionalidade é secundária no processo de ensino. Isso porque o agente principal é o recurso, e o professor atuará como um suporte.) foi marcada por um professor, pois elenca a relevância da finalidade pedagógica prioriza o uso inteiramente do recurso. Essa ideia é errônea, porque recurso nenhum atua sozinho é necessário que exista um professor para mediar o processo de ensino sobre o recurso como um aporte para promover a aprendizagem dos alunos. 
Figura 10: Respostas dos professores da questão 3

O professor deve ter finalidades pedagógicas com o uso dos recursos no ambiente da sala de aula. Por isso, antes que exista a aplicação de algum recurso é necessária que o professor se aproprie de suas funcionalidades, sobre elas realize um planejamento, desenvolva e aplique sua aula articulando recurso com o conteúdo.

$\mathrm{Na}$ intenção de tornar suas aulas de Matemática mais dinâmicas, o professor pode usar qualquer tipo de recurso sem um planejamento prévio e sem associação com o conteúdo abordado em suas aulas.

O professor pode inserir o recurso no ambiente da sala de aula sem um planejamento prévio e durante à aula tentar se apropriar de suas funções em conjunto com seus alunos.

Ao integrar um recurso no ambiente da sala de aula finalidades pedagógicas, o professor deve entender que sua funcionalidade é secundária no processo de ensino. Isso porque o agente principal é o recurso, e o professor atuará como um suporte.

Fonte: Dados da pesquisa

Como exposto na figura 10, a terceira opção (O professor pode inserir o recurso no ambiente da sala de aula sem um planejamento prévio e durante à aula tentar se apropriar de suas funções em conjunto com seus alunos.) não foi escolhida por nenhum professor que leciona Matemática, o que vai de encontro ao debatido na análise a priori.

Esses resultados permitem verificar como e de que maneira os professores investigados podem ou até integram recursos para explorar conhecimentos da Matemática em sala de aula.

De modo distinto às questões $\left(1^{\mathrm{a}}, 2^{\mathrm{a}}\right.$ e $\left.3^{\mathrm{a}}\right)$ já expostas, a quarta questão teve o propósito de compreender a importância que os professores atribuem aos recursos. Por ser uma questão discurssiva, em que os professores responderiam a partir de seus conhecimentos prévios e suas vivências profissionais, na análise a priori tentou-se inferir as possíveis respostas dos professores para as indagações: $1^{\text {a }}$ - Existe algum recurso mais útil que outro para o ensino de conteúdos da Matemática? 2 ${ }^{\mathrm{a}}$ - Qual categoria de recurso você considera mais importante? $3^{\mathrm{a}}$ Por que?

Por ser uma questão discurssiva considerou-se duas opções de respostas: Professores ao responderem não- ao elencarem que não existe um recurso mais útil que outro, deseja-se que os participantes elenquem que todos os tipos de recursos são relevantes para dá suporte ao professor durante o processo de ensino dos conteúdos de Matemática. Essa resposta destacaria que o recurso é apenas um meio para explorar um conteúdo, sendo conduzido pelo professor, para assim promover o aprendizado dos estudantes.

Professores ao responderem sim- em caso afirmativo, que existem recursos mais úteis que outro, infere-se que o tipo a ser destacado seria o Material (tecnologia), seguida pela justificativa de ser muito atual e oferecer dinamismo para as aulas de Matemática.

Ao analisar os resultados dos 15 professores (100\%), obtevê-se as informações expressas na tabela 02 . 
Tabela 02: Respostas dos professores sobre se existe ou não recursos mais úteis que outro

\begin{tabular}{c|c|c}
\hline Categorias de resultados & $\begin{array}{c}\text { Existem recursos mais } \\
\text { úteis que outros }\end{array}$ & $\begin{array}{c}\text { Não existem recursos } \\
\text { mais úteis que outros }\end{array}$ \\
\hline Quantitativo de professores & 2 & 13 \\
\hline Porcentagem & $13,33 \%$ & $86,67 \%$ \\
\hline
\end{tabular}

Fonte: Dados da pesquisa

Como previsto na análise a priori, as respostas dos professores seriam passiveis de elencar que existem ou não recursos mais úteis que outros. Entende-se que os professores ao ressaltarem que existem recursos melhores que outros precisam refletir sobre como integrar materiais no processo de ensino para contribuir como facilitador de conteúdos e assim gerar a aprendizagem de alunos.

Para essa classe de resposta, tem-se a do professor Nosde quando afirma que "Sim! O digital, pois os alunos estão bastante atenados". Esse resultado mostra que é necessário existir formações continuadas para que outros professores reflitam e compreendam com mais ênfase a maneira de trabalhar com recursos, corroborando com o pensamento de Adler (2000).

Dentre os 15 professores (100\%) que participaram dessa investigação, 13 deles $(86,67 \%)$ frisaram que o recurso é um suporte para o professor conduzir o processo de ensino e promover a aprendizagem dos alunos. De forma a representar essa classe de resposta, apresenta-se a de Estela quando ressalta que "Cada recurso é cabivel diante do que se oferece como conteúdo. Muitos são os recursos que podem ser utilizados pelo professor. Por exemplo, o livro didático que é um dos mais usados. Este não é o único necessitando de outros para embasar o planejamento do professor. Outro recurso que gosto de usar é o GeoGebra para abordar os conceitos de geometria e álgebra, enfatizando a dinamicidade de alguns fenômenos matemáticos. Não elencaria uma categoria mais importante, tudo depende da turma, do conteúdo, do tempo didático". Entende-se que esse professor e os demais que acertaram essa questão tem uma maior compreensão de como usar recursos, comparando-se com os professores $(13,33 \%)$ que não alcançaram a resposta esperada.

Os resultados desse estudo destacam a relevância do corpo docente se aprimorar cada vez mais sobre a temática de recurso, seja por meio de oficinas, palestras, minicursos, cursos de curta ou longa duração. Entende-se que alguns participantes apresentaram resultados muitos satisfatórios ao longo do estudo, mas as questões dessa pesquisa (presentes no formulário eletrônico) poderiam explorar outras abordagens ou até ser mais complexas, pois, a ideia do que seja recurso é ampla e necessita de um maior aprofundamento e discussão.entender o que 
são recursos e como abordá-los enquanto um suporte pedagógico é um trabalho construtivo, sendo, portanto, útil discutir essa temática. Aliás, qual professor que leciona Matemática nunca usou recurso? Entretanto, a forma que ele usou foi adequada? Essas são reflexões que possibilitam conhecer e potencializar o uso de recursos como apoio para o trabalho docente.

\section{CONCLUSÕES}

Essa pesquisa ao investigar o entendimento de professores em relação ao que é recursos para o processo do ensino e da aprendizagem se situa no conjunto de estudos do âmbito da Educação Matemática.

Os resultados dessa pesquisa, que participaram 15 professores que lecionam matemática na Educação Básica, convergem com a discussão de Adler (2000) quando destaca que é interessante que exista mais formação para debater sobre o que seja recursos. Verificou-se que os participantes mostraram um desempenho pertinente sobre a noção de recurso e como usá-los no ambiente da sala de aula, mas também a necessidade de aprofundar os tipos e subtipos de recursos com esses profissionais, pois identificou-se que nem todas as respostas corretas foram assinaladas.

Uma limitação desse estudo foi que o trabalho com os professores ocorreu por meio de um questionário eletrônico, ou seja, após resolver às questões não existiu um momento entre pesquisador e pesquisados para debater sobre esse tema para sanar possíveis dúvidas e refletir sobre a abordagem dos recursos. Com isso, não é possível afirmar que os professores desse estudo compreenderam integralmente a proposta do estudo, sendo permitido destacar apenas o que está exposto como respostas no questionário eletrônico.

Por exemplo, no trabalho para explorar a ideia de poliedros (vértices, faces e arestas), o professor poderia se apoiar em tecnologias, materiais manipuláveis, entre outros e todos seriam relevantes para a abordagem do conteúdo. Portanto, o recurso deve ser um aporte para o professor mediar o ensino e promover a aprendizagem para seus alunos.

É interessante que o professor conceba a percepção de que independentemente do tipo ou subtipo de recurso são as ações pedagógicas que permitem ao material atribuir sentido ao conteúdo explorado, por isso é essencial existir um planejamento para integrar um recurso na sala de aula.

Entende-se que os resultados desse estudo podem servir de suporte para futuras formações continuadas de modo a fazer os professores refletirem com mais ênfase sobre a temática de recursos. Assim sendo, sugere-se que próximos estudos analisem a temática de 
recursos com professores que lecionam matemática e que para isso seja elaborado oficinas ou minicursos na intenção de propor atividades de planejamento e práticas no decorrer da vivência.

\section{REFERÊNCIAS}

ADLER, J. Conceptualising resources as a theme for teacher education. Journal of Mathematics Teacher Education. 2000.

BARBOSA, E. J. T; LINS, A. F. Equações polinomiais do primeiro grau em livros didáticos: organizações matemática e didática. Educação Matemática Pesquisa. ISSN 1983-3156. São Paulo, v.15, n.2, p. 337-357, 2013.

BITTAR, M. A Teoria Antropológica do Didático como ferramenta metodológica para análise de livros didáticos. Zetetiké. ISSN 2176-1744. Campinas, SP, v.25, n. 3, p.364-387, set./dez.2017.

BRASIL, S. E. F. Parâmetros curriculares nacionais: matemática/Secretária de Educação Fundamental. Brasília: MEC/SEF,1997. 142 p.

BRASIL, S. E. F. Parâmetros curriculares nacionais: matemática/Secretária de Educação Fundamental. Brasília: MEC/SEF,1998. 148 p.

BRASIL, S. E. F. Base Nacional Curricular Comum- BNCC. Brasília, 2018, p.600.

CARVALHO, J. B. P.; LIMA, P. F. Escolha e uso do livro didático. In: CARVALHO, J.B.P.F. Coleção Explorando o Ensino: Matemática, v. 17. Brasília, MEC, 2010, p. 15- 30.

MONTEIRO, C. E. F. RECURSOS NO ENSINO E APRENDIZAGEM DE MATEMÁTICA EM CONTEXTOS DE EDUCAÇÃO DO CAMPO. In: XII Encontro Nacional de Educação Matemática, 2016, São Paulo. Anais... do XII Encontro Nacional de Educação Matemática. São Paulo: SBEM - Universidade Cruzeiro do Sul, 2016. v. 1. p. 1-12.

PACHÊCO, F. F. F.; ANDRADE, R. L. DE.; SILVA, A. S. DA. O Apprenti Géomètre 2 como um recurso tecnológico para o estudo da comparação de áreas de figuras planas: a apropriação de licenciandos em matemática. REVISTA REAMEC, V.7, p.125-146, 2019.

PACHÊCO, F. F. F.; SILVA, A. S. Atividades sobre comparação de áreas presentes em uma coleção de livros didáticos do $6^{\circ}$ ao $9^{\circ}$ ano do ensino fundamental: um olhar sob os aspectos numéricos e geométricos. Anais... VI Congresso Nacional de Educação (VI CONEDU), 2019, Fortaleza. Anais do VI CONEDU, 2019. V.1. 